\title{
Effects of chronic treatment with commonly used antiepileptic drugs on passive avoidance learning in prepubertal rats
}

\author{
Mehmet Yildirim**, Ismail Abidin', Ali Cansu ${ }^{\mathrm{c}}$ \\ a Department of Physiology, Faculty of Medicine, Karadeniz Technical University, Trabzon, Turkey \\ ${ }^{b}$ Department of Biophysics, Faculty of Medicine, Karadeniz Technical University, Trabzon, Turkey \\ ${ }^{c}$ Department of Pediatric Neurology, Faculty of Medicine, Karadeniz Technical University, Trabzon, Turkey
}

\section{ARTICLE INFO}

\section{Article History}

Received 29/12/2012

Accepted $27 / 01 / 2013$

* Correspondence to:

Mehmet Yildirim

Department of Physiology,

Faculty of Medicine,

Karadeniz Technical University,

Trabzon, Turkey

e-mail: mehmetyildirim@ktu.edu.tr

\section{Keywords:}

Cognitive performance

Epilepsy

Memory

Step-through test

\section{ABSTRACT}

Antiepileptic drugs (AEDs), which are widely used to control and prevent epileptic seizures in children with epilepsy, have potential cognitive side effects. There have been several reports respecting different effects of the first and second generation ADEs on learning and memory. Therefore, we investigated the effects of valproate, carbamazepine, levetiracetam, oxcarbazepine, lamotrigine and topiramate, administered chronically by gavage for 21 days, on learning and memory retention of male and female prepubertal rats. Sixty male and forty-nine female prepubertal Sprague Dawley rats, 21 days old, were used in this study. Cognitive function was tested at 42 days by a step-through passive avoidance task. The results indicated that in both male and female young rats ADEs did not alter passive avoidance latency when compared with the control groups. There is no difference between the effects of the first (valproate and carbamazepine) and second generation ADEs (levetiracetam, oxcarbazepine, lamotrigine and topiramate) regarding learning and memory retention. However, valproate and levetiracetam displayed sexual dimorphism in passive avoidance tast performances. These data suggest that chronic use of both first and second generation ADEs to treat young rats practically could not cause any serious negative effects on cognitive performance.

J. Exp. Clin. Med., 2013; 30:57-61

\section{Introduction}

Epilepsy is one of the most frequent neurological diseases characterized by repeated unprovoked seizures that affect over 50 million people worldwide or approximately 1-2 in 100 human (Hauser, 1994). Antiepileptic drugs (AEDs) are frequently used to restrain and block epileptic seizures but these drugs may cause several side effects (Lagae, 2006). Common adverse effects are reduced attention, motor slowing and moderate memory impairment (Meador et al., 2005). Cognitive and behavioral failures are more common in epileptic patients than in the general population. Seizure-induced impairment of cognitive function in epilepsy patients may result from cell damage in specific brain areas related to learning and memory, as well as from epileptiform activity in the brain (Lynch et al., 1996). Notwithstanding that epilepsy can induce learning and memory dysfunctions, the probable contribution of ADEs to these dysfunctions may describe a significant topic in the treatment of patients with epilepsy who are using drugs for a long time (Mula and Trimble, 2009). Cognitive adverse effects of AEDs are especially important for children than adults (Kuzniecky and Mortati, 2005). Therefore, determining the effects of antiepileptic drugs on cognitive function in individuals with epilepsy is very important with respect to quality of life for patients.

Actually, in spite of AEDs-induced epilepsy restraint can rehabilitate memory; chronic application of AEDs may cause memory impairments. It has been demostrated in a clinical study that valproate (VPA) causes significant impairments in hypothetical thinking, imaginativeness, memory, and mathematic reasoning in patients (Straussberg et al., 1998). VPA was also displayed to impair spatial working memory in rats (Umka et al., 2010). On the other hand, some studies suggest that second-generation AEDs do not unfavorably affect cognitive function like levetiracetam (LEV), oxcarbazepine (OXC) and lamotrigine (LTG) (Lagae, 2006; Donati et al., 2007). Topiramate (TPM) is also a second-generation ADEs and it 
has been associated with particular side effects on memory in children (Coppola et al., 2008). However there are some experimental and clinical studies available which suggest that TPM application has no adverse effects on memory (PerezAlvarez et al., 2006; Nowakowska et al., 2009). According to the literature, the effects of AEDs on learning and memory functions in patients with epilepsy are controversial.

Animal models of learning and memory provides a useful approach for examining the possible effect of AEDs on cognitive functions (Lamberty et al., 2000). To date, there have been no studies investigating and comparing the effects of the first and second generation ADEs on passive avoidance learning and memory in prepubertal non-epileptic rats. Therefore, we aimed to evaluate and compare the effects of chronic treatment with VPA, carbamazepine (CBZ), LEV, OXC, LTG and TPM in male and female rats at postnatal day 21 on a step-through passive avoidance task, which is considered to be simple and reliable examination of learning and memory. We also aimed to test whether the first and second generation ADEs have diverse effects on gender differences in young rats.

\section{Materials and methods \\ Animals}

Sixty male and forty-nine female pre-pubertal Sprague Dawley rats, 21days old and weighing between 41-53 g, were obtained from Karadeniz Technical University Medical Faculty Animal Laboratory and used in this study. Animals were housed under a 12:12 h light-dark cycle (light on at 07:00h) and room temperature of $20 \pm 2^{\circ} \mathrm{C}$. There were no specific restrictions in the diet content and amount administered to the animals in our study. They were given free access to food and water. The controls and drug-administered groups consumed the same food and water. Each application was made to minimize animal suffering and the number of animals used. Experimental procedures were carried out in accordance with the European Communities Council Directive of 24 November 1986 (86/609/EEC) and were approved by the Animal Experimentation Ethics Committee of Karadeniz Technical University.

\section{Experimental design and drug administration}

Male and female rats were divided into 7 groups. Total of 60 male and 49 female rats were into the following experimental groups: (1) the control group was given tap water by oral gavage; (2) the VPA groups was given $300 \mathrm{mg} / \mathrm{kg} /$ day of VPA (Depakin ${ }^{\circ}$; Sanofi Dogu, Istanbul, Turkey); (3) the CBZ group was given $150 \mathrm{mg} / \mathrm{kg} /$ day of CBZ (Tegretol ${ }^{\circledR}$, Novartis, Istanbul, Turkey); (4) the LEV group was given $50 \mathrm{mg}$ / $\mathrm{kg}$ /day of LEV (Vetria ${ }^{\circledR}$, Biofarma, Istanbul, Turkey) (5) the OXC group was given $150 \mathrm{mg} / \mathrm{kg} /$ day of OXC (Trileptal ${ }^{\circledR}$, Novartis, Istanbul, Turkey); (6) the LTG group was given $10 \mathrm{mg} / \mathrm{kg} /$ day of LTG (Lamictal®, Glaxo Smithkline, Istanbul, Turkey); (7) the TPM group was given $100 \mathrm{mg} / \mathrm{kg} /$ day of TPM (Topamax ${ }^{\circledR}$, Johnson \& Johnson, Istanbul, Turkey). Antiepileptic drugs were given in the tap water. The doses of drugs in the treatment groups were defined according to the weights of rats. VPA, CBZ, LEV, OXC, LTG and TPM doses were adopted from literature (Lim and Miller, 1997; Otoom et al., 2004; Cansu et al., 2008; Svalheim et al., 2008). All drugs were administered for 21 days at $12 \mathrm{~h}$ intervals in 2 doses via oral gavage (Fig. 1).

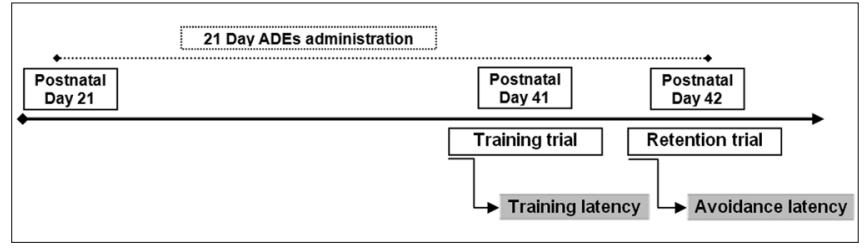

Fig. 1. Schematic explanation of the experimental protocol used in present study. Sixty male and forty-nine female pre-pubertal Sprague Dawley rats, 21days old and weighing between 41$53 \mathrm{~g}$, were used in this study. Male and female rats were divided into 7 groups. VPA, CBZ, LEV, OXC, LTG and TPM were administered for 21 days at 12-h intervals in 2 doses via oral gavage.

\section{Passive avoidance apparatus}

The passive avoidance apparatus consisted of two adjoining compartments, a dark chamber $(20 \times 20 \times 20 \mathrm{~cm})$ with black walls and a light chamber $(20 \times 10 \times 10 \mathrm{~cm})$ with transparent walls. The dark chamber is connected with a light chamber via a guillotine door with dimensions of $5 \times 7 \mathrm{~cm}$. The light chamber was made of a transparent material that was illuminated by a $60 \mathrm{~W}$ light bulb located $50 \mathrm{~cm}$ above the floor. The floor of each compartment consisted of a stainless steel grid with a grid spacing of $1 \mathrm{~cm}$ and $3 \mathrm{~mm}$ in diameter located at $2 \mathrm{~cm}$ above the base of the chamber. The dark compartment contained steel rods capable of delivering an electric shock to the animal's feet. The electroshock apparatus capable of producing a current of $1.5 \mathrm{~mA}$ for any desired time was connected to a grid for delivering footshocks.

\section{Passive avoidance procedure}

To measure the ability of rats to remember a footshock delivered $24 \mathrm{~h}$ earlier, a two-compartment enclosure with shockgrid floor was used. This experiment was carried out as described previously (Yildirim and Marangoz, 2004). On the day of the learning trial, rats were placed in the light chamber of passive avoidance apparatus. The sliding door separating the light and dark chambers was removed $3 \mathrm{sec}$ after the placement of the animals. Chronometer was started once the sliding door was completely lifted. Avoidance latency to enter the dark chamber was recorded. Spontaneous behaviors of animals were also assessed such as the total number of head-pokes (head, including ears). After the animal fully passed the gate and entered the dark chamber, a footshock of $1.5 \mathrm{~mA}$ lasting $3 \mathrm{sec}$ was applied to the animal (the learning trial) by the sliding door separating the compartments was closed. Both chambers of the apparatus were cleaned after each rat to remove any confounding olfactory signals. After $24 \mathrm{~h}$, rats were placed in the light chamber again and observed for 300 s (the test trial). The time delay between the full-body entrances from the light chamber to the dark chamber in the test trial was recorded as the avoidance latency. This latency is a fundamental indicator of memory formation; the shorter the latency, the weaker the memory (Fig. 1).

\section{Statistics}

Avoidance latency was expressed as mean \pm SEM. After the data analyzed via Kruskal Wallis analysis of variance, significance between groups was tested using the Mann-Whitney $\mathrm{U}$ test. $\mathrm{P}$ values that was less than smaller than 0.05 were considered statistically significant. 


\section{Results}

We determined the effects of first- and second-generation AEDs on the passive-avoidance response in male and female prepubertal rats. A dose of ADEs was given orally $2 \mathrm{~h}$ before the training trial. There were no significant differences in training latencies between ADEs groups with their control groups as shown in Table 1. Mean training latencies for male and female rats were $16 \pm 3$ and $19 \pm 4 \mathrm{sec}$, respectively.

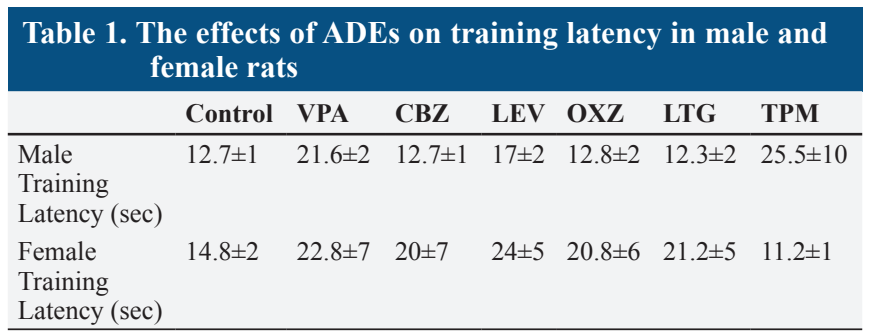

The last dose of ADEs was given orally $2 \mathrm{~h}$ before the retention trial which was carried out the day after the training trial. The test was repeated $24 \mathrm{~h}$ later in the retention trial Kruskal-Wallis test displayed that chronic ADEs treatment did not influence the avoidance latencies with respect to their control group (Table 2,3). In male control rats, the avoidance latency in the retention trial was $273 \pm 16 \mathrm{sec}$., whereas the step-through latency in the training trial was $13 \pm 1 \mathrm{sec}$. in female control rats, the avoidance latency in the retention trial was $266 \pm 31 \mathrm{sec}$ similarly, whereas the step-through latency in the training trial was $15 \pm 2 \mathrm{sec}$. This is clearly indicating that both male and female rats had obtained the passive-avoidance response. In male rats, mean avoidance latencies for $300 \mathrm{mg} /$ $\mathrm{kg}$ VPA, $150 \mathrm{mg} / \mathrm{kg} \mathrm{CBZ,} 50 \mathrm{mg} / \mathrm{kg} \mathrm{LEV}, 150 \mathrm{mg} / \mathrm{kg}$ OXC, $10 \mathrm{mg} / \mathrm{kg}$ LTG and $100 \mathrm{mg} / \mathrm{kg}$ TPM were $300 \pm 0,242 \pm 31$, $125 \pm 45,278 \pm 22,267 \pm 32$ and $293 \pm 6 \mathrm{sec}$, respectively. There were no significant differences between ADEs groups and control group (Table 2,3). $50 \mathrm{mg} / \mathrm{kg}$ LEV administration

\begin{tabular}{|c|c|c|c|c|c|c|c|}
\hline & Control & VPA & CBZ & LEV & OXZ & LTG & TPM \\
\hline $\begin{array}{l}\text { Avoidance } \\
\text { Latency (sec) }\end{array}$ & 273.7 & 300 & 241.9 & 125 & 277.8 & 267.3 & 293.2 \\
\hline SEM & 16 & 0 & 31 & 45 & 22 & 32 & 6 \\
\hline
\end{tabular}

\begin{tabular}{|c|c|c|c|c|c|c|c|}
\hline & Control & VPA & CBZ & LEV & OXZ & LTG & TPM \\
\hline $\begin{array}{l}\text { Avoidance } \\
\text { Latency (sec) }\end{array}$ & 266 & 145.8 & 300 & 268.2 & 233.8 & 196.8 & 300 \\
\hline SEM & 31 & 40 & 0 & 31 & 38 & 41 & 0 \\
\hline
\end{tabular}

decreased the avoidance latency but the difference was not statistically significant when compared to controls. In female rats, mean avoidance latencies for $300 \mathrm{mg} / \mathrm{kg} \mathrm{VPA}, 150 \mathrm{mg} /$ $\mathrm{kg}$ CBZ, $50 \mathrm{mg} / \mathrm{kg} \mathrm{LEV}, 150 \mathrm{mg} / \mathrm{kg}$ OXC, $10 \mathrm{mg} / \mathrm{kg}$ LTG and $100 \mathrm{mg} / \mathrm{kg}$ TPM were $146 \pm 40,300 \pm 0,268 \pm 31,234 \pm 38$, $197 \pm 41$ and $300 \pm 0$ sec., respectively. There were also no significant differences between ADEs groups and control group in female rats (Table 2, 3). $300 \mathrm{mg} / \mathrm{kg}$ VPA reduced the avoidance latency but the difference was not statistically significant when compared to control rats. We finally compared the performances between male and female groups that received the same drug. Interestingly, in VPA and LEV groups there were significant differences $(\mathrm{p}<0.001$ and $\mathrm{p}=0.028$ respectively) (Fig. 2).

\section{Discussion}

In the present study, we tested the hypothesis that secondgeneration antiepileptic drugs (LEV, OXC, LTG, TPM) are less likely to cause cognitive side effects than first-generation antiepileptic drugs (VPA, CBZ) in prepubertal rats. A secondary objective in the current study was to determine whether there were any cognitive differences between male and female rats. Until now, no information regarding cognitive effects of

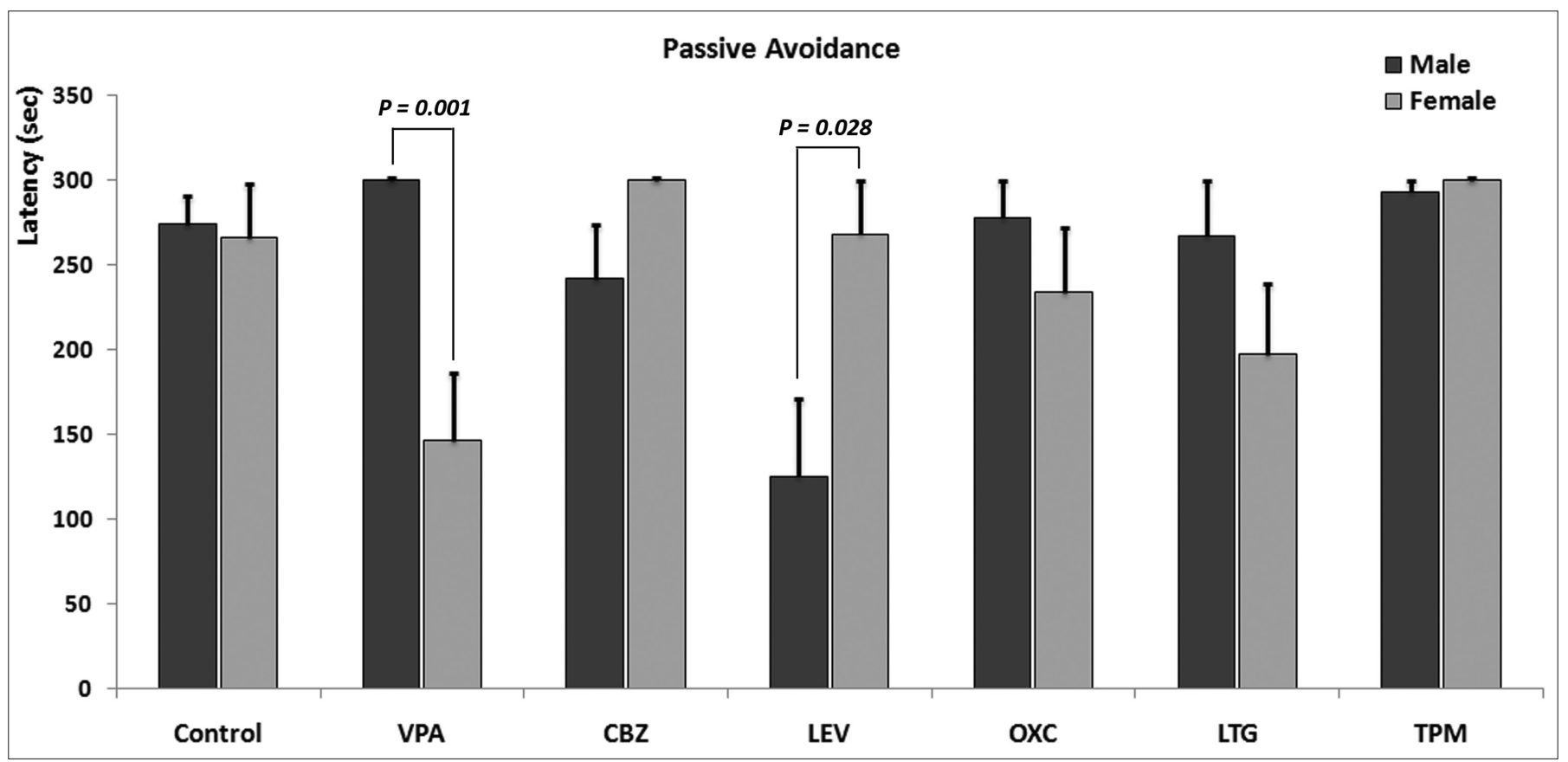

Fig. 2. Passive avoidance performances of the experimental groups. In valproic acid and levetiracetam groups, the sexually dimorphic performances were observed. The cognitive function of VPA received females and LEV received males were significantly reduced compared to the opposite sex that received the same drugs. Values are mean \pm SEM. After the data analyzed via Kruskal Wallis analysis of variance, significance between groups was tested using the Mann-Whitney U test 
first- and second-generation ADEs application in male and female rats during the prepubertal period were available. The passive avoidance test is useful for assessing memory reductions in response to many pharmacological agents (Yildirim and Marangoz, 2004). After our testing we determined that traditional antiepileptic drugs VPA and CBZ did not cause any cognitive changes as compared with control. When the traditional antiepileptic drugs were compared with the new antiepileptic drugs, there were no significant differences in passive avoidance latencies. Presently, our findings showed that in a passive avoidance paradigm learning and memory performance are not impaired by chronic administration of first- and second-generation AEDs during the prepubertal period.

Antiepileptic treatment may decrease the mental and behavioral defects by blocking or lessening the epileptic seizures, but AEDs may also cause unpleasant effects on cognitive functions (Seo et al., 2007). VPA is widely used with a broad spectrum of activity against both generalized and partial epilepsy. It has been usually utilized for the restraint of the neuronal over-excitation by increasing the levels of GABA and the activity of glutamic acid decarboxylase and also via the blockage of voltage-sensitive sodium channels (McLean and Macdonald, 1986). Powerful anti-epileptic properties of VPA, as well as to affect cognitive function, have been reported in the literature with increasing frequency. However, it is still not clear whether VPA has a positive or negative effect on cognitive functions. It has been notified that VPA can impair learning and memory processes both in the experimental models and patients with epilepsy (Yochum et al., 2008; Mula and Trimble, 2009). Several reports have documented the mild/moderate cognitive defects in adult patients treated with VPA (Carpay et al., 2005). Cognitive capabilities were also normalized when VPA was discontinued (Lossius et al., 2008).

A recent study showed that VPA can cause cognitive deterioration in adult male Lister Hooded rats which are connected with changes in hippocampal neurogenesis and neurotrophin levels (Umka et al., 2010). In contrast to these studies, Sirén and co-worker showed that visual memory and delicate motor continuity were enhanced in children treated with VPA (Sirén et al. 2007). TPM is a newer AED, which is widely used for infantile spasms and complex partial seizures in children. It was reported that $20 \mathrm{mg} / \mathrm{kg}$ TPM but not $100 \mathrm{mg} / \mathrm{kg}$ TPM significantly reduced short-term memory deficits on Morris water maze performance in rats with pilocarpine-induced status epilepticus. While neuroprotective effects of $100 \mathrm{mg} / \mathrm{kg}$ TPM were observed in hippocampal CA area, cell loss after application of $20 \mathrm{mg} / \mathrm{kg}$ TPM was indiscernible from group receiving diazepam only (Frisch et al., 2007). Little is known as yet about the influences of LEV, another new antiepileptic drug, on learning and memory functions. An experimental study reported that LEV has been stated to have beneficial cognitive effects in a scopolamine-induced amnesia model in mice and in water-maze task in rats (Zhou et al., 2007).

Limited studies have compared second-generation AEDs to traditional AEDs but several reports have suggested that newer AEDs such as lamotrigine, topiramate and gabapentin may have less effects on cognitive functions than conventional AEDs drugs (Martin et al., 1999). Second-generation AEDs appear to be more positive than the traditional drugs with respect to adverse cognitive effects (Aldenkamp et al., 2003). For instance, cognitive performance in the Morris water maze test was not changed by the doses of LEV (17$54-170 \mathrm{mg} / \mathrm{kg}$ ) known to suppress motor seizures in normal and amygdala-kindled rats. In contrast, higher doses of VPA (200-300 mg/kg), CZP (0.3-1 mg/kg), and CBZ (40-60 mg/ $\mathrm{kg}$ ) decreased learning performance of both non-epileptic and kindled epileptic rats (Lamberty et al., 2000). Recently, a non-interventional study shows that compared with CBZ, LEV has slightly but absolutely superior effects on cognition in both pretreated and non-pretreated patients (Helmstaedter and Witt, 2010). In studies comparing the adverse effects of LTG with other AEDs on cognitive function in healthy volunteers have showed fewer side effects for LTG than for CBZ, VPA and TPM (Meador et al., 2001; Meador et al., 2005). A retrospective study also showed that LTG and OXC monotherapies in epilepsy patients have similar positive cognitive effects (Seo et al., 2007).

In the present study we have observed a sexual dimorphism in the effects of VPA and LEV. The cognitive function of VPA received females and LEV received males were significantly reduced compared to the opposite sex that received the same drugs. The sex dependent differeces in cognitive functions are well documented (Kanit et al., 2003; Rücker et al., 2004). Brain responses to environmental or psychological stimuli may differ between genders (Dalla et al., 2008; Harte and Dow-Edwards, 2010). In our study, it can be proposed that LEV and VPA affected the learning performance by a mechanism that expressed differently between genders. To clarify how these two antiepileptic drugs affect the cognitive performance in a sexually dimoprhic way further behavioral and mechanistic studies are necessary.

Investigation of potential side effects of AEDs on learning and memory in non-epileptic animals may be helpful for safe and effective medication in people with epilepsy, especially young people with epilepsy. It has been widely reported in the literature that antiepileptic drugs (AEDs) can cause cognitive side effects (Aldenkamp et al., 2003). But in the present study there were no significant effects of AEDs on learning parameter in young rats. Our results show that chronic administration of first- (VPA, CBZ) and second-generation (LEV, OXC, LTG, TPM) AEDs did not prevent the learning of the passive-avoidance response and memory formation for both male and female prepubertal rats. In conclusion, the present findings offer evidence that the long-term use of traditional or new ADEs do not impair cognitive performance in young male and female rat, at least at the doses used in this study.

\section{REFERENCES}

Aldenkamp, A.P., De Krom, M., Reijs, R., 2003. Newer antiepileptic drugs and cognitive issues. Epilepsia. 44, 21-29.

Cansu, A., Giray, S.G., Serdaroglu, A., Erdogan, D., Coskun, Z.K., Korucuoglu, U., Biri, A.A., 2008. Effects of chronic treatment with valproate and oxcarbazepine on ovarian folliculogenesis in rats. Epilepsia. 49, 1192-1201.

Carpay, J.A., Aldenkamp, A.P., Van Donselaar, C.A., 2005. Complaints associated with the use of antiepileptic drugs: Results from a communitybased study. Seizure. 14, 198-206. 
Coppola, G., Verrotti, A., Resicato, G., Ferrarelli, S., Auricchio, G., Operto, F.F., Pascotto, A., 2008. Topiramate in children and adolescents with epilepsy and mental retardation: A prospective study on behavior and cognitive effects. Epilepsy Behav. 12, 253-256.

Dalla, C., Edgecomb, C., Whetstone, A.S., Shors, T.J., 2008. Females do not express learned helplessness like males do. Neuropsychopharmacology. 33, 1559-1569.

Donati, F., Gobbi, G., Campistol, J., Rapatz, G., Daehler, M., Sturm, Y., Aldenkamp, A.P., Oxcarbazepine Cognitive Study Group., 2007. The cognitive effects of oxcarbazepine versus carbamazepine or valproate in newly diagnosed children with partial seizures. Seizure. 16, 670679.

Frisch, C., Kudin, A.P., Elger, C.E., Kunz, W.S., Helmstaedter, C., 2007. Amelioration of water maze performance deficits by topiramate applied during pilocarpine-induced status epilepticus is negatively dose-dependent. Epilepsy Res. 73, 173-180.

Harte, L.C., Dow-Edwards, D., 2010. Sexually dimorphic alterations in locomotion and reversal learning after adolescent tetrahydrocannabinol exposure in the rat. Neurotoxicol. Teratol. 32, 515-524.

Hauser, W.A., 1994. The prevalence and incidence of convulsive disorders in children. Epilepsia. 35, 1-6.

Helmstaedter, C., Witt, J.A., 2010. Cognitive outcome of antiepileptic treatment with levetiracetam versus carbamazepine monotherapy: A noninterventional surveillance trial. Epilepsy Behav. 18, 74-80.

Kanit, L., Koylu, E.O., Yararbas, G., Furedy, J.J., Pogun, S., 2003. The effect of nitric oxide synthase inhibition on cognitive ability and strategies employed for place learning in the water maze: Sex differences. Brain Res. Bull. 62, 151-159.

Kuzniecky, R.I., Mortati, K., 2005. Practical strategies for switching to newer antiepileptic drugs. Rev. Neurol. Dis. 2, $186-198$.

Lagae, L., 2006. Cognitive side effects of anti-epileptic drugs. The relevance in childhood epilepsy. Seizure. 15, 235-241.

Lamberty, Y., Margineanu, D.G., Klitgaard, H., 2000. Absence of negative impact of levetiracetam on cognitive function and memory in normal and amygdala-kindled rats. Epilepsy Behav. 1, 333-342.

Lim, J., Miller, M.G., 1997. Role of testis exposure levels in the insensitivity of prepubertal rats to carbendazim-induced testicular toxicity. Fundam Appl Toxicol. 37, 158-167.

Lossius, M.I., Hessen, E., Mowinckel, P., Stavem, K., Erikssen, J., Gulbrandsen, P., Gjerstad, L., 2008. Consequences of antiepileptic drug withdrawal: A randomized, double-blind study (Akershus Study). Epilepsia. 49, 455-463.

Lynch, M.W., Rutecki, P.A., Sutula, T.P., 1996. The effects of seizures on the brain. Curr. Opin. Neurol. 9, 97-102.

Martin, R., Kuzniecky, R., Ho, S., Hetherington, H., Pan, J., Sinclair, K., Gilliam, F., Faught, E., 1999. Cognitive effects of topiramate, gabapentin, and lamotrigine in healthy young adults. Neurology. 52, 321-327.

McLean, M.J., Macdonald, R.L., 1986. Sodium valproate, but not ethosuximide, produces use- and voltage-dependent limitation of high frequency repetitive firing of action potentials of mouse central neurons in cell culture. J. Pharmacol Exp. Ther. 237, 1001-1011.

Meador, K.J., Loring, D.W., Ray, P.G., Murro, A.M., King, D.W., Perrine, K.R., Vazquez, B.R., Kiolbasa, T., 2001. Differential cognitive and behavioral effects of carbamazepine and lamotrigine. Neurology. 56, 1177-1182.

Meador, K.J., Loring, D.W., Vahle, V.J., Ray, P.G., Werz, M.A., Fessler, A.J., Ogrocki, P., Schoenberg, M.R., Miller, J.M., Kustra, R.P., 2005. Cognitive and behavioral effects of lamotrigine and topiramate in healthy volunteers. Neurology. 64, 2108-2114.

Mula, M., Trimble, M.R., 2009. Antiepileptic drug-induced cognitive adverse effects: Potential mechanisms and contributing factors. CNS Drugs. 23, 121-137.

Nowakowska, E., Kus, K., Czubak, A., Jedrzejewska, J., 2009. Memory improving and antidepressant effects of topiramate in rats. Arzneimittelforschung 59, 487-492.

Otoom, S., Batieneh, H., Hassan, Z., Daoud, A., 2004. Effects of long-term use Topiramate on fertility and growth parameter in adult male rats. Neuro. Endocrinol Lett. 25, 351-355.

Perez-Alvarez, F., Timoneda-Gallart, C., Baus-Rosell, J., 2006. Topiramate and epilepsy in the light of Das-Naglieri Cognitive Assessment System. Rev. Neurol. 42, 3-7.

Rücker, B., Pereira, G.S., Fürstenau, C.R., Izquierdo, I., Bonan, C.D., Sarkis, J.J., 2004. Inhibitory avoidance task reveals differences in ectonucleotidase activities between male and female rats. Neurochem. Res. 29, 2231-2237.

Seo, J.G., Lee, D.I., Hwang, Y.H., Lee, H.W., Jung, D.K., Suh, C.K., Kwon, S.H., Park, S.P., 2007. Comparison of cognitive effects of lamotrigine and oxcarbazepine in epilepsy patients. J. Clin. Neurol. 3, 31-37.

Sirén, A., Kylliäinen, A., Tenhunen, M., 2007. Beneficial effects of antiepileptic medication on absence seizures and cognitive functioning in children. Epilepsy Behav. 11, 85-91.

Straussberg, R., Kivity, S., Weitz, R., Harel, L., Gadoth, N., 1998. Reversible cortical atrophy and cognitive decline induced by valproic acid. Eur. J. Paediatr. Neurol. 2, 213-218.

Svalheim, S., Taubøll, E., Surdova, K., Ormel, L., Dahl, E., Aleksandersen, M., McNeilly, A., Gjerstad, L., Ropstad, E., 2008. Long-term levetiracetam treatment affects reproductive endocrine function in female Wistar rats. Seizure. 17, 203-209.

Umka, J., Mustafa, S., ElBeltagy, M., Thorpe, A., Latif, L., Bennett, G., Wigmore, P.M., 2010. Valproic acid reduces spatial working memory and cell proliferation in the hippocampus. Neurosci. 166, 15-22.

Yildirim, M., Marangoz, C., 2004. Effects of nitric oxide on passive avoidance learning in rats. Int. J. Neurosci. 114, 597-606.

Yochum, C.L., Dowling, P., Reuhl, K.R., 2008. VPA induced apoptosis and behavioral deficits in neonatal mice. Brain Res. 1203, $126-132$.

Zhou, J.L., Zhao, Q., Holmes, G.L., 2007. Effect of levetiracetam on visual-spatial memory following status epilepticus. Epilepsy Res. 73, 6574. 